spring meetings were not to become as obsolescent as a gathering of wainwrights. The fragmenting force was clearly that of the necessity and the compelling ascendancy of specialization.

"In modern times the constituent branches of medical science are so expanded that they are not acquired by any physician in a lifetime, and still less by a pupil in his pupilage. The same is true even of individual branches." This early example of Harvard angst appeared in the Boston Medical and Surgical Journal in 1850, before even the pathogenesis of infectious disease was firmly established (9). In subsequent generations, "the explosive growth of the constituent branches of medical science" continues to fragment medicine into subdisciplines based on organ systems or even on technologies. As an example, in 2007 a small town of cardiologists $(>20,000)$ convened in Orlando, as one of the few venues that could accommodate the American Heart Association annual meeting. Topics as diverse as myocardial regeneration from stem cells and resuscitation science were among the more than 4,000 abstracts submitted for that multitude. Similar gatherings occur annually for all of the other major specialty societies, many of which are themselves further fragmenting into sub-subdisciplines increasingly circumscribed. As do the general societies, the specialists also face the challenge of Yeats's often-quoted line "things fall apart; the center cannot hold," a poetic statement of universal entropy (10). In contrast to academic surgery, no specialties have as yet split off as separate and distinct islands from internal medicine, but a number of expanding peninsulas are clearly apparent. One need not doubt that the science and technology of medicine, in their totality, are more effectively transmitted when spread out thin through many such societies with vast numbers of committed and sharply focused participants. After all, in science, as in life, a truly well-rounded individual may be in danger of having a short radius. One can doubt, however, whether the most important legacy of Atlantic City, the culture and cohesiveness of academic internal medicine, is effectively transmitted thereby.

Fortunately within the current leadership of the spring meetings, Samuel Johnson's view of history has largely prevailed. Let us hope that in a future generation, someone in an analogous fashion to the above will find it attractive to compose a brief "Homage to Chicago" as a uniquely valuable and singular era and setting for academic internal medicine.

Address correspondence to: Lloyd H. Smith, 309 Evergreen Drive, Kentfield, California, 94904, USA. Phone: (415) 461-1553; Fax: (415) 467-3946; E-mail: lloydhsmith@aol.com.

1. McNabb, M. 1916 May 25. A close-up of Henry Ford. Chicago Daily Tribune. 8.

2. Johnson, S. 1759. The history of Rasselas, Prince of Abissinia. Chapter 30.

3. Means, J.H. 1961. The Association of American Physicians: its first seventy-five years. McGraw-Hill. New York, New York, USA. 123-131.

4. Harvey, A.M. 1986. The Association of American Physicians 1886-1986: a century of progress in medical science. Waverly Press. Baltimore, Maryland, USA. 680 pp.

5. Earley, L.E. 1976. The health of clinical investigation beyond Atlantic City. Presidential address before the 68th annual meeting of the American Society for Clinical Investigation, Atlantic City, New Jersey, 3 May 1976. J. Clin. Invest. 57:1660-1665.

6. Moore, C.V. 1954. Proceedings of the forty-sixth annual meeting of the American Society for Clinical Investigation held in Atlantic City, N.J., May 4, 1954. J. Clin. Invest. 33:912-913.

7. Smith, L.H. 1976. Presidential address. Trans. Assoc. Am. Physicians. 89:1-9.

8. Landefeld, C.S. 1993. The Spring Meetings - are they dying? N. Engl. J. Med. 328:1645-1647.

9. Medical Faculty of Harvard University. 1850. Practical views on medical education. Boston Medical and Surgical Journal. XLII:24-35.

10. Yeats, W.B. 1920 November. The second coming. The Dial. Volume 69.

\title{
Atlantic City and the Boardwalk: 1932-1976
}

\author{
Donald W. Seldin
}

Department of Internal Medicine, University of Texas Southwestern Medical Center, Dallas, Texas, USA.

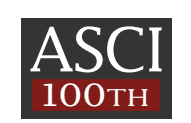

\begin{abstract}
Memories of the meetings in Atlantic City of the two major academic medical societies, the AAP and the ASCI, are enveloped by a vague and unsettling nostalgia. Dominating the scene was the Boardwalk - a site of unexpected encounters, often with long-forgotten colleagues, evoking a feeling of shared intellectual excitement and rich personal ties.
\end{abstract}

The feeling of congeniality at the Atlantic City meetings of the AAP and the ASCI was reinforced by a variety of social features. The graciousness and extensive public spaces of the meeting's official hotel, Chalfonte-Haddon Hall - the comfortable lounges, meandering lobby, shielded sun porch - provided ample opportunity for small gatherings, unexpected reunions, and private exchanges. Various rituals reinforced the feelings of festive reunion: the Surf'n Sand Bar, Brighton Punch, the late lobster dinner at Hackney's (Figure 1) all contributed to a feeling of community and warmth.

From 1932 until 1976, the societies met only in Atlantic City. It should be remembered that during this interval, regional meetings were few and specialty meetings virtually nonexistent.

Conflict of interest: The author has declared that no conflict of interest exists. Citation for this article: J. Clin. Invest. 118:1227-1228 (2008). doi:10.1172/JCI34921.
As a consequence, the finest research was presented here to a relatively small group of academic scholars. Presentation the Congress Hall on the Steel Pier was the ultimate goal of budding investigators no less than exalted professors. The core of medicine was reasonably accessible to nearly everyone, since high technology, conceptual as well as technical, did not yet dominate the medical disciplines. It was a thrill to present a paper to a select, high-level audience, among whom were many hallowed figures in academic medicine.

The Atlantic City meetings nurtured the finest medical research embraced by a rich climate of academic collegiality. Maybe the science is much better now - more sophisticated, more reductive, with far greater explanatory power. Maybe the central focus on physiologic derangements yielded less profound insight into normal and deranged function than the genetic and molecular biology of today. Maybe the huge teams of investigators, bringing 


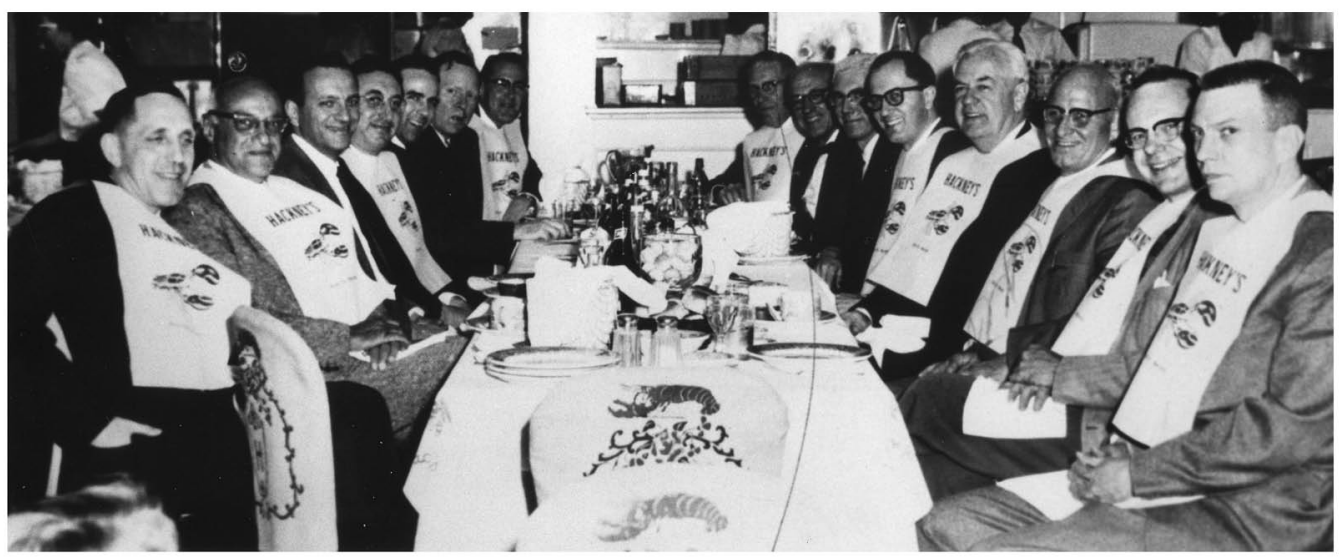

Figure 1

A group of diners at Hackney's Restaurant in Atlantic City, 1959. Left, front to back: Charles G. Spicknall, Marion B. Sulzberger, Morris Ziff, Joseph B. Kirsner, John H. Vaughan, Samuel Martin, and Max Miller. Right, front to back: John Rumball, Frank H. Tyler, Julian M. Ruffin, Arthur Colwell, Donald W. Seldin, Wade Volwiler, Franz J. Inglefinger, and Ivan Duff.

together diverse disciplines, are far more powerful than the more solitary system of the past. Maybe the medical manager is the more appropriate leader than the medical scholar.

But something has been sacrificed. The central core of medicine has become gravely weakened; the warmth of academic life has to some extent been replaced by impersonality and distance. And specialty meetings command the major scientific advances.

It would be foolish not to recognize the tremendous power of modern medical science. Everyone must surely acknowledge the enormous advance that is the product of specialization, technology, and conceptual analysis. But still, the attractiveness of the
Atlantic City meetings - the qualities of shared knowledge, common goals, and warm friendships, reinforced by a congenial and familiar environment - constitute profound human values. The new biology may well be our ultimate medical triumph. But it would be nice to imagine how rich life would be if a little of the Boardwalk could be injected into the modern academic world.

Address correspondence to: Donald W. Seldin, Department of Internal Medicine, University of Texas Southwestern Medical Center, 5323 Harry Hines Boulevard, Dallas, Texas 75390-9030. USA. Phone: (214) 648-3804; Fax: (214) 648-9100.

\section{The American Society for Clinical Investigation, 1952-1975: a personal perspective}

\section{Eugene Braunwald}

TIMI Study Group, Cardiovascular Division, Brigham and Women's Hospital, and Department of Medicine, Harvard Medical School, Boston, Massachusetts, USA.

In this perspective, I trace my experiences with the ASCI, beginning in 1952, when as a medical student I attended my first meeting, until 1975, when I completed my term as president of the Society. I focus attention on the sociological aspects of the Atlantic City meetings and the critically important role these meetings played in the evolution of academic medicine during the third quarter of the 20th century.

The period encompassed by this article begins in 1952 with the first meeting of the American Society for Clinical Investigation that I attended and ends with the 1975 meeting, when I completed my year as president and graduated to emeritus membership. In 1952 Harry Truman was the president of the United States and the Korean War was in full swing. Research was rarely carried out by medical students at the time, but I was fortunate to have been

Conflict of interest: The author has declared that no conflict of interest exists. Citation for this article: J. Clin. Invest. 118:1228-1230 (2008). doi:10.1172/JCI34653. given the opportunity to spend an extended research elective in the hemodynamic research laboratory of Ludwig Eichna at New York University and Bellevue Hospital. We studied the hemodynamics of heart failure, a subject that I have worked on intermittently since then and continue to investigate at present. Eichna was the secretary of the ASCI and therefore was quite involved in Society matters. He talked to me about them at some length, giving me a bird's-eye view, and arranged for me to accompany him to the annual meeting in Atlantic City, New Jersey, then a quiet seaside resort. 